\title{
Injection Molding and Compression Molding of Polyamide $10.10^{+}$
}

\author{
George Mihail Teodorescu ${ }^{1}$, Zina Vuluga ${ }^{1,}{ }^{*}$, Mariana Osiac ${ }^{2}$, Nicoleta Levinta ${ }^{1}$, \\ Cristian Andi Nicolae ${ }^{1}$, Raluca Augusta Gabor ${ }^{1}$, Andreea Afilipoaei ${ }^{1}$ and \\ Mihai Cosmin Corobea ${ }^{1}$
}

\author{
1 National Institute for Research and Development in Chemistry and Petrochemistry-ICECHIM, \\ 202 Spl. Independenței, 060021 Bucharest, Romania; georgemihail.teodorescu@yahoo.com (G.M.T.); \\ nicoleta.levinta@yahoo.com (N.L.); ca_nicolae@yahoo.com (C.A.N.); ralucagabor@yahoo.com (R.A.G.); \\ andreea.afilipoaei@yahoo.com (A.A.); mcorobea@yahoo.com (M.C.C.) \\ 2 Department of Physics, University of Craiova, A.I. Cuza 13, 200585 Craiova, Romania; \\ mariana71osiac@gmail.com \\ * Correspondence: zvuluga@yahoo.com \\ + Presented at the 16th International Symposium "Priorities of Chemistry for a Sustainable Development" \\ PRIOCHEM, Bucharest, Romania, 28-30 October 2020.
}

Published: 11 November 2020

Keywords: bio-based polyamide; injection molding; compression molding

In today's industry, molding is a common process used to manufacture a product or a component with the use of heat and pressure. Polyamide 10.10 (PA1010) is a semi crystalline polymer with emerging applications in industry due to its promising mechanical properties and relatively low melting temperature [1-3]. However, there are not many studies regarding the behavior and properties of PA1010 through different molding processes other than injection molding. The objective of this study is to compare and correlate the structural, thermal and nanomechanical properties of PA1010 samples subjected to different molding processes in order to establish the structure-processing-properties interdependence.

A commercial polyamide (PA10.10) was used and processed in dynamic conditions by melt processing in order to obtain samples (PA1010-I and PA1010-C) through injection molding (PA1010-I) and compression molding (PA1010-C). Structural analysis was done with a Shimadzu 6000 X-ray diffractometer while thermal analysis was performed with DMA Q800, TGA Q5000 and DSC Q2000 and the nanomechanical properties (reduced modulus-Er, hardness-H, roughness and coefficient of friction) were obtained using a TI Premier system (Hysitron Inc., Minneapolis, MN, USA).

XRD analysis revealed a main contribution for the macromolecular structure's orientation from the $\alpha$ and $\gamma$ phases. PA1010-C has a more oriented structure compared to PA1010-I due to the processing method. Thermal analysis shows small differences between the two materials with PA1010-C having a higher thermal stability. Nanomechanical analysis showed that PA1010-C properties increased over $40 \%$ for Er and H compared to PA1010-I but as a result presents a lower degree of elastic recovery. Nano-scratching shows very low values of roughness and coefficients of friction for PA1010-C compared to PA1010-I meaning that the surface properties are heavily dependent on the processing method and correlate well with the XRD analysis.

Due to its applications, PA1010 may be used in several industries based on the processing method. The properties of polyamide 10.10 rely on the processing method in close correlation with the structural behavior and, respectively, with the nanomechanical properties. 
Acknowledgments: This work was supported by a grant of the Romanian Ministry of Research and Innovation, CCCDI-UEFISCDI, project number PN-III-P1-1.2-PCCDI-2017-0387/80PCCDI Tehnologii emergente pentru valorificarea industriala a structurilor 2 D (grafenice si nongrafenice) Acronym EMERG2Ind, within PNCDI III.

\section{References}

1. Pagacz, J.; Raftopoulos, K.N.; Leszczyńska, A.; Pielichowski, K. Bio-polyamides based on renewable raw materials. J. Therm. Anal. Calorim. 2016, 123, 1225-1237.

2. Quiles-Carrillo, L.; Boronat, T.; Montanes, N.; Balart, R.; Torres-Giner, S. Injection-molded parts of fully bio-based polyamide 1010 strengthened with waste derived slate fibers pretreated with glycidyl- and amino-silane coupling agents. Polym. Test. 2019, 77, 105875.

3. Winnacker, M.; Rieger, B. Biobased polyamides: Recent advances in basic and applied research. Macromol. Rapid Commun. 2016, 37, 1391-1413.

Publisher's Note: MDPI stays neutral with regard to jurisdictional claims in published maps and institutional affiliations.

(C) 2020 by the authors. Licensee MDPI, Basel, Switzerland. This article is an open access article distributed under the terms and conditions of the Creative Commons Attribution (CC BY) license (http://creativecommons.org/licenses/by/4.0/). 